\title{
Novel Deep Eutectic Solvent Based on Levulinic Acid and 1,4-Butanediol as an Extraction Media for Bioactive Alkaloid Rutaecarpine
}

\author{
Yue-Yue Si ${ }^{1}$, Shi-Wei Sun ${ }^{1}$, Kun Liu ${ }^{2}$, Yang Liu ${ }^{1}$, Hai-Lin Shi ${ }^{1}$, Ke Zhao ${ }^{1}$, Jin Wang ${ }^{1}$ and \\ Wei Wang 1,*(D) \\ 1 Department of Natural Medicine and Pharmacognosy, School of Pharmacy, Qingdao University, \\ Qingdao 260021, China; syy2016qd@163.com (Y.-Y.S.); sunsw@qdu.edu.cn (S.-W.S.); \\ buckuper@163.com (Y.L.); shihailinjin@163.com (H.-L.S.); Qingdao_zhaoke@163.com (K.Z.); \\ Qingdao_wangjin@163.com (J.W.) \\ 2 Department of Drug Metabolism and Analysis, School of Pharmacy, Qingdao University, Qingdao 260021, \\ China; kunliu62@126.com \\ * Correspondence: w.w.wangwei@263.net; Tel./Fax: +86-532-8699-1172
}

Received: 4 March 2019; Accepted: 21 March 2019; Published: 24 March 2019

\begin{abstract}
Deep eutectic solvents (DESs) are increasingly receiving interest as a new type of green and sustainable alternative to hazardous organic solvents. In this work, a novel DES based on levulinic acid (La) and 1,4-butanediol (Buta) as an extraction media was developed for extracting the bioactive alkaloid rutaecarpine from the unripe fruits of Tetradium ruticarpum. 24 different DESs consisting of choline chloride, betaine, sugar alcohols, organic acids, amides, and sugars were prepared and tailored to test their extraction efficiency. After initial screening, a hydrophilic DES composed of La and Buta with 1:0.5 molar ratio containing 25\% water was tailored for the highest extraction efficiency, followed by the optimizations of molar ratio and water content. The interaction between the molecules of La-Buta DES was investigated by nuclear magnetic resonance spectroscopy in order to confirm its deep eutectic supermolecular structure feature. The extraction conditions were optimized by single-factor experiments, including extraction temperature, extraction time, and solid-liquid ratio. The developed La-Buta DES extraction procedure was successfully applied for the analysis of rutaecarpine in Chinese patent medicines containing the unripe fruits of T. ruticarpum. The excellent property of La-Buta DES indicated its potential as a promising green solvent instead of conventional organic solvent for the extraction of rutaecarpine from the unripe fruits of T. ruticarpum, and that it can used as a sustainable and safe extraction media for other applications.
\end{abstract}

Keywords: deep eutectic solvents; indolopyridoquinazolinone alkaloid; rutaecarpin; Tetradium ruticarpum; Zuojin Pill; Wuji Pill

\section{Introduction}

Alkaloids are defined by the presence of a heterocyclic nitrogen atom, and have been increasingly attracting pharmaceutical researchers to develop therapeutic agents as lead compounds [1-3]. Indole alkaloids are characterized by the presence of a structural moiety of indole, and have been extensively studied as they possess important biological properties such as antihypertension [4], antihistamine [5], anticonvulsant [6], anti-leishmanial [7], antidiabetic [8], anti-HIV-1, anti-inflammatory [9], anticancer [10], and antibacterial activities [11]. They are present in several plant families as secondary metabolites, including the Strychnaceae, Apocynaceae, Rutaceae, and Rubiaceae [10]. Rutaecarpine is an indolopyridoquinazolinone alkaloid with diverse biological activities which is one of the main components isolated from the unripe fruits of the traditional Chinese medicine Tetradium ruticarpum 
(A. Jussieu) T. G. Hartley (synonym: Euodia ruticarpa) (Figure 1) [12-15]. The beneficial properties of rutaecarpine have led to a high demand for extracts containing rutaecarpine in the pharmaceutical industry. One of the critical and preliminary steps before any application lies in the extraction [16]. Because of the low solubility of rutaecarpine in water, organic solvents and their aqueous solutions have been widely used as solvents for the extraction of rutaecarpine in combination with various extraction methods [17-20]. Nevertheless, the consumption of massive amounts of these hazardous and volatile organic solvents may contribute to environmental pollution, and leave objectionable solvent residues in extracts [21]. Supercritical fluid extraction with carbon dioxide was used to extract rutaecarpine from the unripe fruits of T. ruticarpum [22]. Supercritical carbon dioxide is relatively safe, but pure supercritical carbon dioxide does not have sufficient solvation power, and thus a polar co-solvent methanol has to be added to carbon dioxide in order to increase rutaecarpine's solubility. Deep eutectic solvents (DESs) are considered to be a novel class of green solvent because they are formed by simply mixing two or more components with some advantages such as negligible volatility, non-flammability, non-toxicity, biodegradability, and thermal stability [23]. Furthermore, DESs possess high solubilization power strength for a wide range of compounds, especially poorly water-soluble compounds [24]. All these properties make them of interest for applications in health-related areas such as pharmaceuticals, foods, and cosmetics. Jiang et al. studied the extraction of rutaecarpine from the unripe fruits of T. ruticarpum using DESs consisted of choline chloride $(\mathrm{ChCl})$ and hydrogen bond donors (HBDs), such as organic acids (lactic acid (Laa) and levulinic acid (La)), amides (acetamide (Ace) and urea (Ur)), sugar alcohols (ethylene glycol (Eg) and glycerol (Gly)), and sugars (D-glucose (Glu) and maltose (Mal)). Unfortunately, the results showed that only ChCl-La DES produced similar extraction efficiency for rutaecarpine with methanol [25]. More research is required to make tailor-made DESs as green solvents to extract rutaecarpine from the unripe fruits of T. ruticarpum. Following the work of Jiang et al., we prepared a series of betaine(Bet)-based and organic acid-based DESs and measured a number of properties of these DESs. Utilization of the prepared DESs for the extraction of rutaecarpine from the unripe fruits of T. ruticarpum was explored. After initial screening, La and 1,4-butanediol (Buta) with 2:1 molar ratio containing 25\% water was tailored for the highest extraction efficiency, followed by the optimization of molar ratio and water content. The supermolecular structure of La-Buta DES was investigated with nuclear magnetic resonance (NMR) spectroscopy. The extraction conditions, including extraction temperature, time, and solid-liquid ratio, were further optimized by single-factor experiments. The developed La-Buta DES extraction procedure was successfully applied for the analysis of rutaecarpine in Chinese patent medicines containing the unripe fruits of T. ruticarpum.

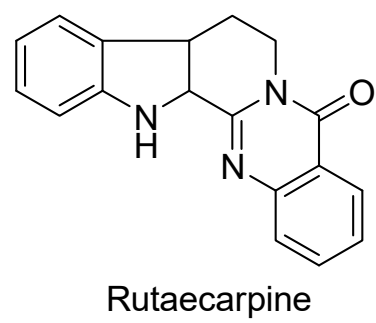

Figure 1. The structure of rutaecarpine.

\section{Materials and Methods}

\subsection{Reagents and Materials}

Compounds used for DESs preparation including $\mathrm{ChCl}$, Bet, La, xylitol (Xyl), and D-sorbitol (Sor) were acquired from Energy Chemical Company (Shanghai, China), and Eg, Buta, Gly, oxalic acid (Ox), DL-malic acid (Ma), citric acid (Ca), Ur, Ace, and Glu were from Aibi Chemical Reagent Company (Shanghai, China). The reference compound of rutaecarpine was obtained from DESITE Biotech (Chengdu, China). The purity reference compound was determined to be $>98 \%$ by high-performance 
liquid chromatography (HPLC) analysis, and its structure was shown in Figure 1. For $\mathrm{pH}$ and polarity measurements, Nile red (Sigma-Aldrich, St. Louis, MO, USA) and a series of standard pH buffers (Shanghai INESA \& Scientific Instrument, Shanghai, China) were used. HPLC-grade acetonitrile was bought from Thermo Fisher Scientific (Waltham, MA, USA). Analytical-grade methanol and $\mathrm{pH}$ 0-14 universal $\mathrm{pH}$-indicator strips were supplied by Beijing Chemical Industry Group (Beijing, China). Deionized water was purified by a Milli-Q water purification system from Millopore (Bedford, MA, USA). The dried unripe fruits of T. ruticarpum were purchased from a local traditional Chinese medicine marker (Qingdao, China), and authenticated by Prof. Yingxia Li, School of Pharmacy, Qingdao University. The Chinese patent medicines were obtained at the local drugstore, including Zuojin Wan (Hubei Xianglian Pharmaceutical Co., Ltd., Lichuan, China) and Wuji Wan (Li Shizhen Pharmaceutical Group Co., Ltd., Qichun, China).

\subsection{Preparation and Physicochemical Properties Tests of DESs}

All the DESs were prepared using the heating and stirring method according to previous studies [26,27]. Different components in a proper molar ratio were mixed in the round-bottomed flask with magnetic agitation using a DF-101S collector-type constant temperature heating magnetic stirrer (Yuhua Instruments, Gongyi, China) at $85^{\circ} \mathrm{C}$ until a stable homogeneous liquid was formed. All the prepared DESs were allowed to cool to room temperature. The physicochemical properties of DES solutions were tested as mixtures that were prepared by mixing the produced DES with additional water 75:25 $(w / w)$. Solvent $\mathrm{pH}$ was measured using a PHS-3C pH benchtop meter (Shanghai INESA \& Scientific Instrument, Shanghai, China) calibrated using a series of standard $\mathrm{pH}$ buffers prior to use. Viscosity was obtained with a Brookfield DV-III Ultra rheometer (Brookfield, Middleboro, MA, USA) at $25{ }^{\circ} \mathrm{C}$. Polarity testing was done with Nile red as a solvatochromatic probe to estimate polarity of DES in the form of molar transition energy $\left(E_{N R}\right)$. A Nile red solution was prepared at $10 \mu \mathrm{g} / \mathrm{mL}$ in ethanol, and added to the reference solvent and DES solution, after which the samples were placed in a $1 \mathrm{~cm}^{3}$ quartz cuvette. The absorption maxima of the solution $\left(\lambda_{\max }\right)$ was recorded on a Shimadzu UV2600 UV-Visible spectrophotometer (Shimadzu, Kyoto, Japan) and the molar transition energy was calculated using the following formula: $\mathrm{E}_{\mathrm{NR}}(\mathrm{kcal} / \mathrm{mol})=\mathrm{hcN}_{\mathrm{A}} / \lambda_{\max }=28,591 / \lambda_{\max }$, where $\mathrm{h}$ is Planck's constant, $c$ is the speed of light in a vacuum, and $N_{A}$ is the Avogadro constant $[24,28,29]$.

\subsection{Extraction Procedure Using Different Solvents}

The dried unripe fruits of T. ruticarpum were ground into powder using an FW177 electric disintegrator (Tianjin Taisite Instruments, Tianjin, China), and sieved by a 60 mesh stainless steel sieve. Samples of $0.5 \mathrm{~g}$ of powdered plant material were soaked in $25 \mathrm{~mL}$ of different solvents (methanol, $80 \%$ aqueous methanol, $v / v$, water, and DESs) for $60 \mathrm{~min}$, and then extracted with a KQ-500E ultrasonic bath $\left(500 \mathrm{~W}, 20 \mathrm{kHz}\right.$, Kushan Ultrasonic Instrument, Kushan, China) at $35^{\circ} \mathrm{C}$ for $40 \mathrm{~min}$. After the above treatment, all extracts were filtered through a $0.45 \mu \mathrm{m}$ membrane filter (Jinteng Nylon 66, Tianjin Jinteng Experimental Equipment, Tianjin, China) before HPLC analysis. All the experiments were carried out in triplicate.

\subsection{Opimization of Extraction Conditions}

After initial screening of extraction solvents, La-Buta DES was chosen to optimize the extraction conditions. The conditions included each extraction temperature $\left(25,35,45,55\right.$, and $\left.65^{\circ} \mathrm{C}\right)$, extraction time $(10,20,30,40,50$, and $60 \mathrm{~min})$, and solid-liquid ratio (1:10, 1:20, 1:30, 1:40 and 1:50). The effect of ultrasonic power was not investigated, and $500 \mathrm{~W}, 20 \mathrm{kHz}$ was directly adopted.

\subsection{HPLC-UV Analysis for Quantification of Rutaecarpine}

Quantitative HPLC analysis was performed on an Agilent 1260 system equipped with a G1311C quaternary pump, a G1329B autosampler, a G1314F variable wavelength detector coupled with an analytical workstation, a 1316A thermostated column compartment, and separation on a Zorbax 
SB-C18 column $(250 \mathrm{~mm} \times 4.6 \mathrm{~mm}, 5 \mu \mathrm{m})$ at $35{ }^{\circ} \mathrm{C}$ (Agilent technologies, Santa Clara, CA, USA). The mobile phase consisted of water with $0.2 \%$ phosphoric acid (A) and acetonitrile (B). The gradient elution program was as follows: $0-20 \mathrm{~min}, 10-30 \% \mathrm{~B} ; 20-60 \mathrm{~min}, 30-70 \% \mathrm{~B} ; 60-70 \mathrm{~min}, 70 \% \mathrm{~B}$ at a constant flow rate of $1.0 \mathrm{~mL} / \mathrm{min}$. The detection wavelength was monitored at $345 \mathrm{~nm}$. The chromatographic peak of rutaecarpine was confirmed by comparing its retention time with that of the reference compound. The injection volume was set at $10 \mu \mathrm{L}$. The standard stock solution of rutaecarpine was prepared by dissolving a weighted amount in methanol to give a final concentration of $708.8 \mu \mathrm{g} / \mathrm{mL}$. The standard working solutions were prepared by diluting the stock solution with methanol to obtain a concentration range of 1.4176 to $24.0992 \mu \mathrm{g} / \mathrm{mL}$. Quantitative determination was performed by the external standard method. The data are present as the mean value \pm standard deviation of three replicated samples.

\subsection{NMR Spectroscopy}

The ${ }^{1} \mathrm{H}$ NMR and ${ }^{1} \mathrm{H}-{ }^{1} \mathrm{H}$ nuclear overhauser enhancement spectroscopy (NOESY) spectra of the diluted La-Buta DES with deuterated dimethyl sulfoxide were performed at $27^{\circ} \mathrm{C}$ on a Bruker AV-500 FT-NMR spectrometer (500.13 MHz proton frequency, Burker Daltonics, Bremen, Germany). For the ${ }^{1} \mathrm{H}$ NMR spectrum, a total of 65,536 data points were recorded, covering a spectral window of $13,020.8 \mathrm{~Hz}$; 32 scans of a standard one-pulse sequence with $90^{\circ}$ flip angle for excitation and presaturation during $2.0 \mathrm{~s}$ of relaxation delay. An exponential window function with a line-broadening factor of $0.3 \mathrm{~Hz}$ was applied prior to a Fourier transformation. The resulting spectrum was manually phased and baseline corrected. The NOESY spectrum was obtained with presaturation $\left(B_{1}=50 \mathrm{~Hz}\right)$ during a relaxation delay of $2.0 \mathrm{~s}$. A data matrix with $1024 \times 1024$ points covering $6068.0 \times 6068.0 \mathrm{~Hz}$ was recorded with 32 scans for each increment. Data were zero filled to $2048 \times 2048$ points prior to State-TPPI type 2D Fourier transformation and a sine bell-shaped window function was applied in both dimensions. Mixing time was $80 \mathrm{~ms}$.

\section{Results and Discussion}

\subsection{Evaluation of Analytical Method}

To obtain better separation between the peak of rutaecarpine and other peaks, the chromatographic conditions were optimized. Different types of columns [ZORBAX Eclipse XDB-C18, ZORBAX Extent-C18, ZORBAX SB-C18 (250 mm $\times 4.6 \mathrm{~mm}, 5 \mu \mathrm{m}$, Agilent technologies, Santa Clara, CA, USA), and Generall-M C18 $(250 \mathrm{~mm} \times 4.6 \mathrm{~mm}, 5 \mu \mathrm{m}$, Guangzhou Yanchuang Biotechnologies, Guangzhou, China)], column temperatures $\left(25,30,35\right.$, and $\left.40{ }^{\circ} \mathrm{C}\right)$, flow rates $(0.8 .1 .0$, and $1.2 \mathrm{~mL} / \mathrm{min})$, mobile phases (methanol-water and acetonitrile-water), types of acid (formic acid, acetic acid, and phosphoric acid), and concentrations of additive $(0.05 \%, 0.1 \%$, and $0.2 \%)$ were optimized. The optimum HPLC conditions acquired a proper separation between the peak of rutaecarpine and other peaks. The HPLC chromatograms of the reference compound of tutecarpine and the typical extract sample of $\mathrm{T}$. ruticarpum were shown in Figure 2.

To evaluate the proposed analytical method, a series of experiments were designed to access the linearity, limit of quantification, limit of detection, precision, and recovery. The calibration curve contained eight concentrations, and was established with a range of 1.4176 to $24.0992 \mu \mathrm{g} / \mathrm{mL}$. The linear regression equation was established as $y=5062.2 x+3.0$ with a good linear correlation coefficient $\left(R^{2}\right)$ of 0.9996 , in which $y$ was the peak area of the analyte, and $x$ was the mass of the analyte. Based on the signal to noise ratio $(\mathrm{S} / \mathrm{N})$ of 10 and 3 , the limit of quantification and limit of detection were $3.54 \mathrm{ng}$ and $0.71 \mathrm{ng}$, respectively. For inter-day precision, the typical sample was determined six times on the same day, and the RSD was $0.87 \%$. For intra-day precision, the sample was measured on three different days, and the RSD was $1.94 \%$. The recovery was assessed by a spiking standard solution of rutaecarpine at three different concentration levels into the sample method. The higher recoveries of rutaecarpine in the range of $97.2-103.5 \%$ were obtained. 

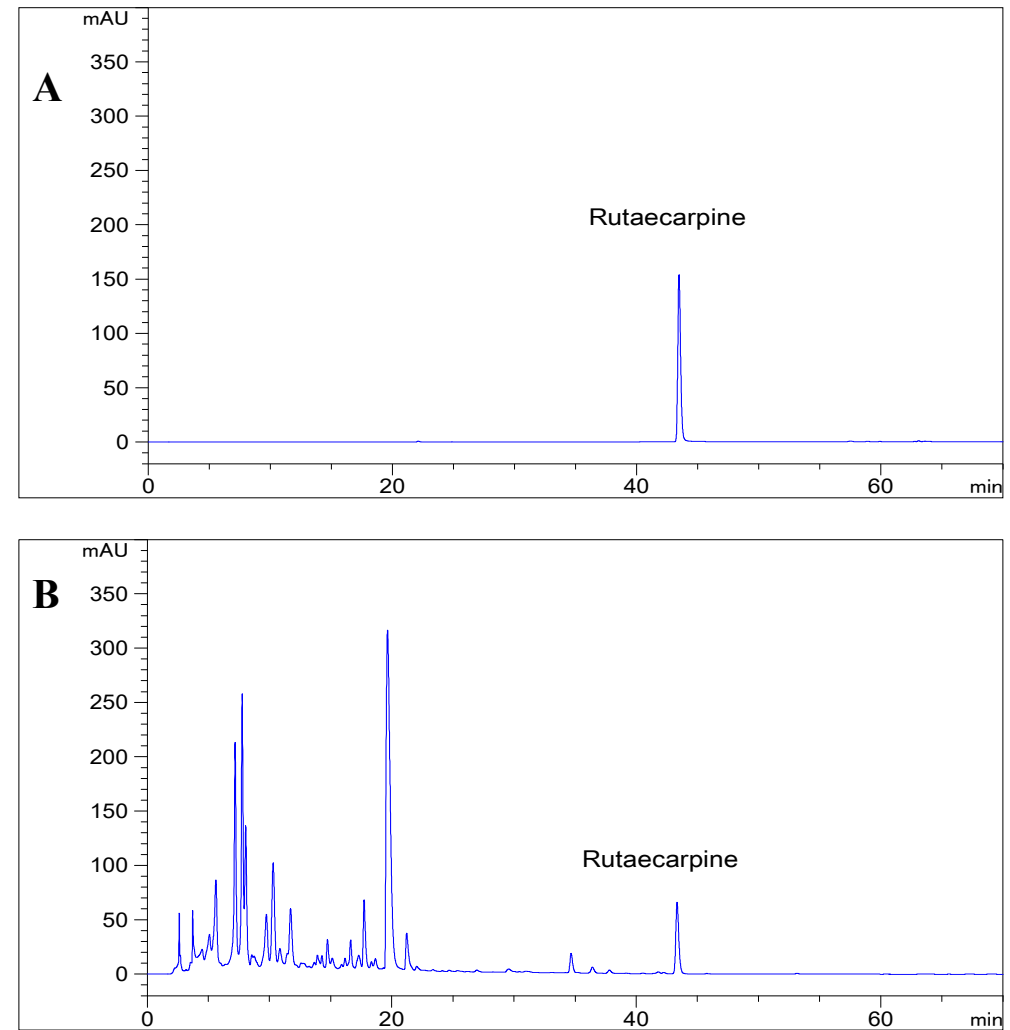

Figure 2. Typical HPLC chromatograms of (A) the reference compound of rutaecarpine, and (B) the extract of T. ruticarpum. HPLC conditions: Column, Zorbax SB-C18 $250 \mathrm{~mm} \times 4.6 \mathrm{~mm}$ I.D.; column temperature, $35{ }^{\circ} \mathrm{C}$; mobile phase, water with $0.2 \%$ phosphoric acid (A) and acetonitrile (B); gradient program, 0-20 min, 10-30\% B; 20-60 $\mathrm{min}, 30-70 \% \mathrm{~B} ; 60-70 \mathrm{~min}, 70 \% \mathrm{~B}$; flow rate, $1.0 \mathrm{~mL} / \mathrm{min}$, detection wavelength, $345 \mathrm{~nm}$.

\subsection{Preparation of Various Types of DESs}

DESs have been applied for extraction of bioactive flavonoids, terpenes, saponins, anthraquinones, alkaloids, and phenolic acids [23,24,30]. Heating and stirring, evaporating, and freeze-drying techniques that could be adjusted with some temperature and time modifications are available for DES preparation [16]. In this work, the heating and stirring method was used, since several DESs can be prepared simultaneously, and its procedure is simple. In principle, DESs can result from the right combination of hydrogen bond acceptors (HBAs) and HBDs that are capable of hydrogen bond interactions. One of the most widely used $\mathrm{HBAs}$ is $\mathrm{ChCl}$, which is a non-toxic, inexpensive, and biodegradable quaternary ammonium. Bet has a similar structure to $\mathrm{ChCl}$, and can be used as the HBA.

Based on the previous reports [27,30,31], $\mathrm{ChCl}$ and Bet were chosen as the HBAs to prepare DESs with 15 HBDs including five sugar alcohols (Eg, Buta, Gly, Xyl, and Sor), four organic acids (Ox, $\mathrm{La}, \mathrm{Ma}, \mathrm{Ca}$ ), two amides (Ace and $\mathrm{Ur}$ ), and one sugar (Glu) at various molar ratios (Tables 1 and 2). Recent discoveries showed that many combinations of primary plant metabolites, such as organic acids, sugars, and sugar alcohols with adjusted proportions change their state from solid to liquid [32]. In this study, we prepared nine organic acid-based DESs, composed of primary plant metabolites, including four DESs, La-Buta, La-Gly, Ma-Gly, and Ca-Glu reported for the first time. Although the literature reported a number of organic acid-based DESs, however, unlike $\mathrm{HBAs}, \mathrm{ChCl}$ and Bet-based DESs, no physicochemical properties were found for the formed liquids. Herein, the preliminary physicochemical characterizations including solvent $\mathrm{pH}$, viscosity, and polarity of the nine prepared organic acid-based DESs were measured (Table 3). Totally, 24 DESs were prepared as homogeneous 
liquids without crystal precipitation. After preparation, the DESs were stored in sealed vials for several days before use.

Table 1. 75\% ChCl-based DESs solutions tested for extraction.

\begin{tabular}{clccc}
\hline Abbreviation & HBA & HBD & Molar Ratio & Water Content (\%) \\
\hline ChCl-Eg & choline chloride & ethylene glycol & $1: 2$ & 25 \\
ChCl-Buta & choline chloride & 1,4-butanediol & $1: 2$ & 25 \\
ChCl-Gly & choline chloride & glycerol & $1: 2$ & 25 \\
ChCl-Ox & choline chloride & oxalic acid & $1: 1$ & 25 \\
ChCl-La & choline chloride & levulinic acid & $1: 2$ & 25 \\
ChCl-Ma & choline chloride & DL-malic acid & $3: 2$ & 25 \\
ChCl-Ca & choline chloride & citric acid & $2: 1$ & 25 \\
ChCl-Ur & choline chloride & urea & $1: 2$ & 25 \\
ChCl-Ace & choline chloride & acetamide & $1: 2$ & 25 \\
ChCl-Glu & choline chloride & D-glucose & $1: 1$ & 25 \\
\hline
\end{tabular}

Table 2. 75\% Bet-based DESs solutions tested for extraction.

\begin{tabular}{ccccc}
\hline Abbreviation & HBA & HBD & Molar Ratio & Water Content (\%) \\
\hline Bet-Gly & betaine & glycerol & $1: 2$ & 25 \\
Bet-Xyl & betaine & xylitol & $1: 1$ & 25 \\
Bet-Sor & betaine & D-sorbitol & $5: 6$ & 25 \\
Bet-La & betaine & levulinic acid & $1: 2$ & 25 \\
Bet-Ma & betaine & DL-malic acid & $1: 2$ & 25 \\
\hline
\end{tabular}

Table 3. Abbreviations and properties of 75\% organic acid-based DES solutions tested for extraction.

\begin{tabular}{cccccc}
\hline Abbreviation & Molar Ratio & Water Content (\%) & $\mathbf{p H}$ & $\begin{array}{c}\left.\text { Viscosity } \mathbf{( 2 5}^{\circ} \mathbf{C}\right) \\
\left(\mathbf{m m}^{\mathbf{2}} \mathbf{s} \mathbf{)}\right.\end{array}$ & $\begin{array}{c}\mathbf{E}_{\mathbf{N R}} \\
\mathbf{( k c a l / m o l )}\end{array}$ \\
\hline La-Xyl & $1: 1$ & 25 & 2.02 & 47.59 & 49.13 \\
La-Gly & $1: 1$ & 25 & 1.83 & 11.00 & 49.29 \\
La-Buta & $1: 1$ & 25 & 2.23 & 9.60 & 49.47 \\
Ma-Gly & $1: 1$ & 25 & 1.05 & 45.39 & 47.89 \\
Ma-Glu & $1: 1$ & 25 & 0.82 & 107.20 & 48.46 \\
Ca-Xyl & $1: 1$ & 25 & 0.74 & 160.00 & 47.65 \\
Ca-Gly & $1: 2$ & 25 & 1.06 & 63.79 & 47.89 \\
Ca-Glu & $1: 1$ & 25 & 0.62 & 157.00 & 48.21 \\
Ca-Sor & $1: 1$ & 25 & 1.13 & 196.00 & 47.81 \\
\hline
\end{tabular}

\subsection{Supermolecular Structure of La-Buta DES}

DESs are generally produced by mixing two or more components that are capable of self-association to form a eutectic mixture with a melting point that is below that of the individual compounds [33]. Hydrogen-bonding interactions are the main diving force of this phenomenon [34]. Up to now, a large number of DESs with different composition and molar ratio have been reported in the literatures. However, no melting points were found for the formed liquids. Instead, all of them were showing a much lower glass-transition temperature than expected [35]. Francisco, van den Bruinhorst, and Kroon named them "low-transition-temperature mixtures", and not DESs. So, it is very important to check whether a hydrogen-bonding network via intermolecular interactions in the supermolecular structure of DESs is formed. NOESY was applied to investigate molecular interactions between the components of these DESs. Dai and co-worker observed strong interactions between the protons on the hydroxyl groups from $\mathrm{ChCl}-1,2-$ propanediol-water and proline-Ma-water [32]. In our study, the interaction between the molecules of La-Buta DES was investigated by NOESY in order to confirm its deep eutectic supermolecular structure feature. The correlations between the protons on the carboxyl group of La, the hydroxyl group of Buta, and water, were observed in the NOESY 
spectrum, implying that hydrogen bonds are formed between these carboxyl groups and hydroxyl groups, and water might also participate in the supermolecular structure of DES (Figure 3).

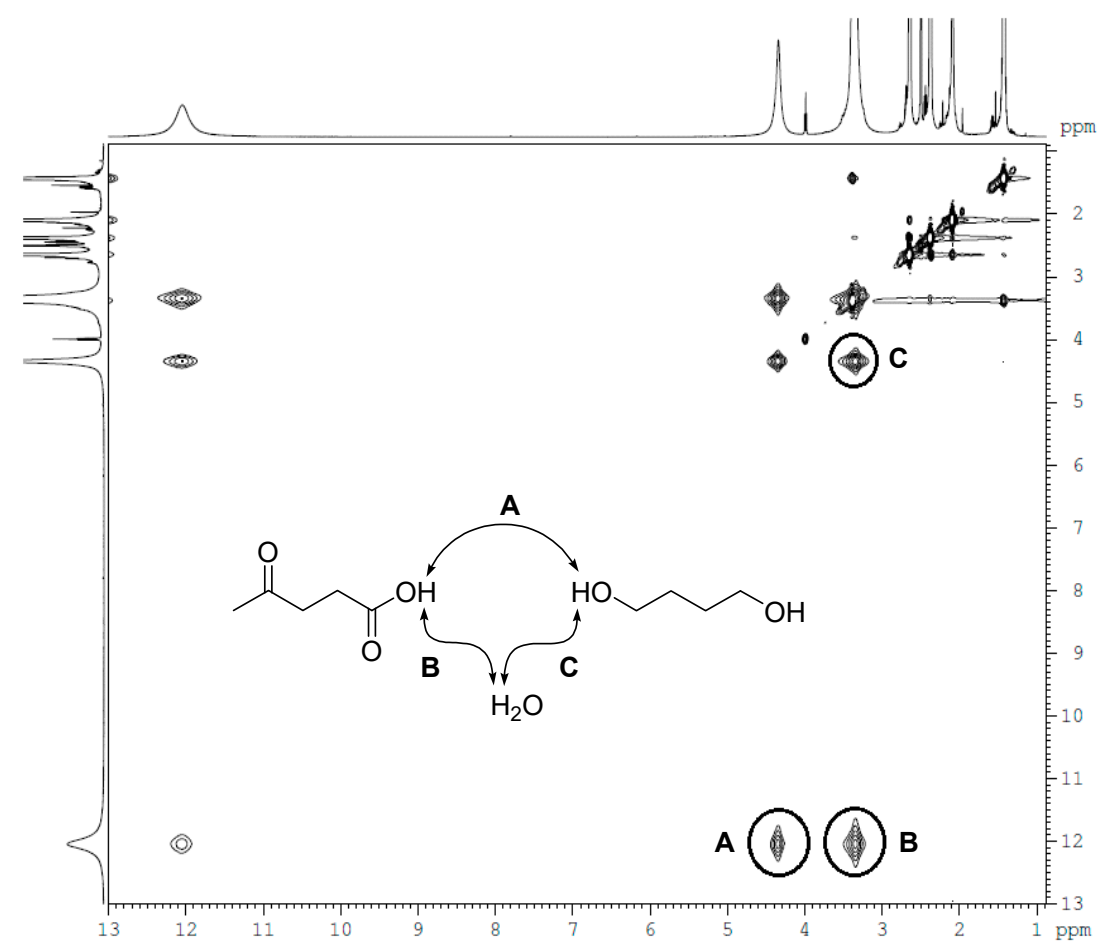

Figure 3. NOESY spectrum of La-Buta DES. (A) correlation between the protons on the carboxyl group of La, and the hydroxyl group of Buta; (B) correlation between the protons on the carboxyl group of La and water, and; $(\mathbf{C})$ correlation between the protons on the hydroxyl group of Buta and water.

\subsection{Selection of Initial Extraction Condition}

One of the criteria for green extraction is to reduce energy consumption by using innovative technologies such as microwave- and ultrasound-assisted extractions [36]. Herein, this ultrasound-assisted extraction method was applied in the screening procedure. Based on previous studies [19,37], three solvents, including methanol, $80 \%$ aqueous methanol $(v / v)$, and water were evaluated as reference extraction solvents.

Comparison of methanol and $80 \%$ aqueous methanol $(v / v)$ revealed that $80 \%$ aqueous methanol $(v / v)$ was more effective for rutaecarpine extraction, although the differences were not statistically significant $(p>0.05, n=3)$. The methanol and $80 \%$ aqueous methanol $(v / v)$ were significantly superior to water $(p<0.0001, n=3)$. As a result, $80 \%$ aqueous methanol $(v / v)$ was selected as the reference extraction solvent for any subsequent comparison of extraction efficiencies of various DESs. Compared to conventional solvents, the major disadvantage of DESs is their inherent high viscosity. To solve this problem, all of the DESs were tested as mixtures that were prepared by mixing the produced DES with additional water 75:25 $(w / w)$. The addition of water to the DESs at this ratio facilitated solvent handing by significantly reducing their viscosity, while still maintaining the supermolecular structures of the DESs [27,28]. It was reported that DESs prepared by heating and stirring, evaporating, and freeze-drying methods contained small amounts $(5-10 \%, w / w)$ of water $[28,38]$. For convenience, it must be noted that these DESs were used as extraction media without considering themselves water content in this study.

\subsection{DESs Selection for Extraction}

To find the best extraction solvent for rutaecarpine, the prepared DESs with different properties were examined in this study. The content of rutaecarpine determined by HPLC was employed to assess 
the extraction efficiency of DESs. As shown in Figures 4 and 5, the capacities of the prepared DESs for extracting rutaecarpine varied considerably, depending on their chemical compositions. For $\mathrm{ChCl}$ and Bet-based DESs, sugar alcohols, sugars, and amides in combination with them, exhibited relatively low extraction capacity, whereas those associated with La allowed extracting rutaecarpine at higher yields. For example, ChCl-La produced similar extraction efficiency for rutaecarpine compared with $80 \%$ aqueous methanol $(v / v)$, which is in agreement with the previous report [24]. It must be noted that the extraction yield obtained with $\mathrm{ChCl}-\mathrm{Ox}$ was higher than that obtained with $\mathrm{ChCl}-\mathrm{La}$. Among the carboxylic acid-based DESs, it could be found that DES made of La and Buta for rutaecarpine possessed the highest extraction yield than others. The high extraction yield may be related to its viscosity, polarity, and $\mathrm{pH}$ values. In our study, since the water-diluted carboxylic acid-based DESs had polarity values ranging from 47 to $49 \mathrm{kcal} / \mathrm{mol}$, which are similar to that of water [27], the relationship between the polarity of the DES and the extractability of rutaecarpine cannot be found. Similarly, it was not possible to find any correlation with the basic and acid nature of the DES solutions and their extraction yields. Ma-Gly and Ca-Gly solutions have the same $\mathrm{pH}$ values, but different extractabilities. On the other hand, Ma-Glu and Ma-Bet solutions have the different $\mathrm{pH}$ values but similar extraction yields of rutaecarpine. The viscosity of the DESs containing sugar alcohols or carboxylic acids is mainly affected by the hydrogen bonding interaction, which increases with numbers of hydroxyl and carboxyl groups. Therefore, the order of the viscosities is correlated with the number of hydroxyl and carboxyl groups in chemical compositions of DESs ( $\mathrm{La}<\mathrm{Ma}<\mathrm{Ca}$ and Buta $<\mathrm{Gly}<\mathrm{Xyl}$ ). Our results showed some clear inverse correlations of the extraction yield and viscosity. For Ca-Gly, Ma-Gly, and La-Gly solutions, the viscosities decrease from Ca-Gly to La-Gyl, which increase the extractabilities. However, we also observed some contradictory facts of the extraction yield and viscosity. For La-Buta, La-Gly, and La-Xyl solutions, the viscosities increase from La-Buta to La-Xyl, but La-Xyl presents similar efficiency comparable to La-Buta. So, our results also indicate that the rutaecarpine extraction efficiencies of DESs appear to be affected by multiple factors [27].

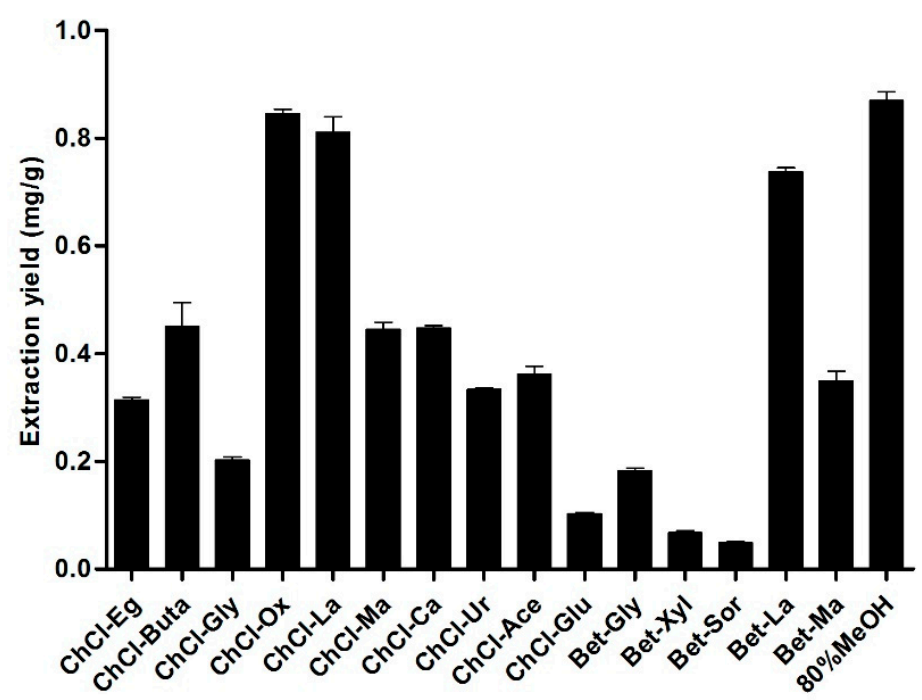

Figure 4. Rutaecarpine extraction yields of $75 \% \mathrm{ChCl}$ and Bet-based DESs solutions, and the reference solvent $80 \%$ aqueous methanol $(v / v)$ for comparison. Varied DES aqueous solution was used as a solvent to extract at a solid-liquid ratio of $1: 50$ with ultrasound at $35^{\circ} \mathrm{C}$ and $500 \mathrm{~W}$ for $40 \mathrm{~min}$. Data represent mean \pm S.D. of triplicated experiments. 


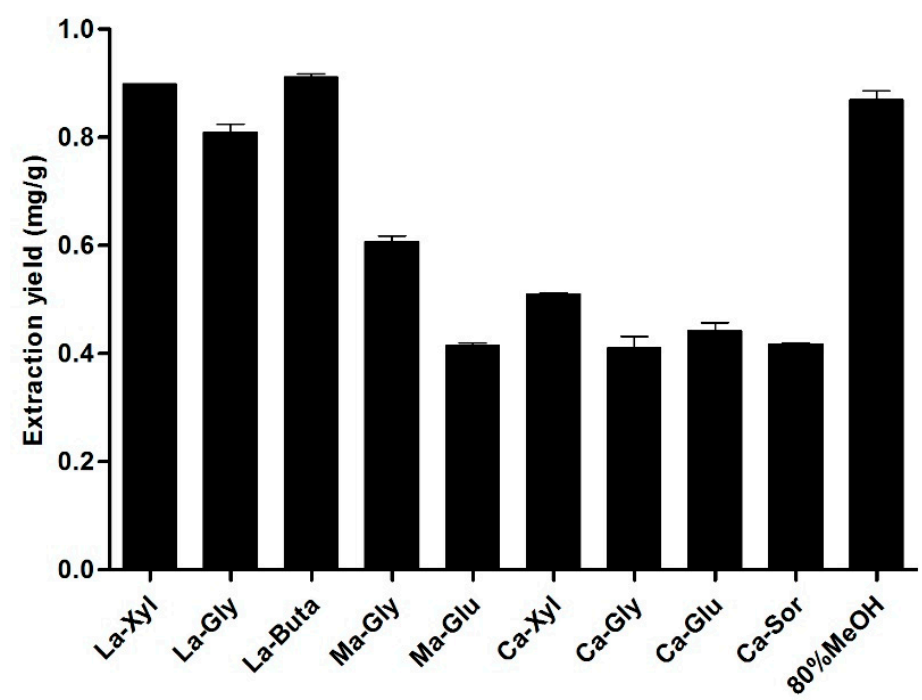

Figure 5. Rutaecarpine extraction yields of $75 \%$ organic acid-based DESs solutions and reference solvent $80 \%$ aqueous methanol $(v / v)$ for comparison. Varied DES aqueous solution was used as solvent to extract at a solid-liquid ratio of $1: 50$ with ultrasound at $35^{\circ} \mathrm{C}$ and $500 \mathrm{~W}$ for $40 \mathrm{~min}$. Data represent mean \pm S.D. of triplicated experiments.

\subsection{Effect of the Molar Ratio of La and Buta}

Different molar ratios of the components of DES may differ in physiochemical properties and extraction capacities. The effects of different molar ratios of La and Buta in 1:0.5, 1:1, and 1:2 on the extraction yield of rutaecarpine were tested. As depicted in Figure 6, the molar ratio of La to Buta increasing from 1:0.5 to 1:1 would lead to a decrease in extraction efficiency. However, the extraction yield increased, with the molar ratio increasing from 1:1 to 1:2. Comparatively speaking, the highest extraction yield was achieved by a molar ratio of 1:0.5, and thus was chosen for further study.

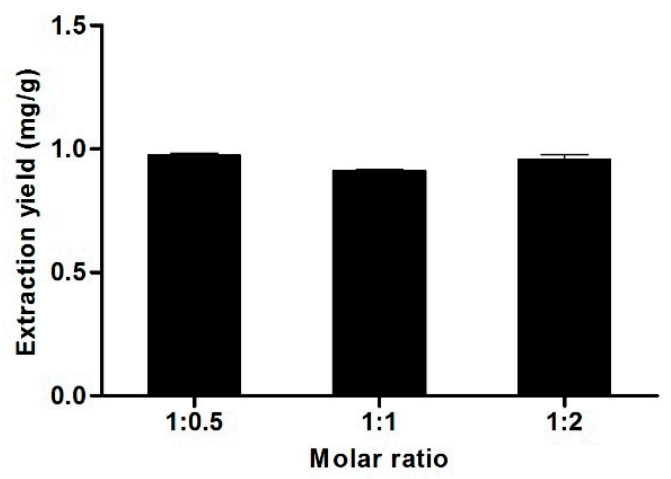

Figure 6. Rutaecarpine extraction yields of La-Buta DESs with different molar ratios. La-Buta DES aqueous solution with different molar ratios was used as the solvent to extract at a solid-liquid ratio of $1: 50$ with ultrasound at $35{ }^{\circ} \mathrm{C}$ and $500 \mathrm{~W}$ for $40 \mathrm{~min}$. Data represent mean \pm S.D. of triplicated experiments.

In order to attain more insight into the supermolecular structures of different molar ratios of La and Buta, ${ }^{1} \mathrm{H}$ NMR spectrum was used to analyze the relative numbers of detected protons on the carboxyl group and hydroxyl group (relative to the protons on the methyl group for La and unoxygenated methylene for Buta). As shown in Table 4, the highest integral areas of hydroxyl groups were integrated in the ${ }^{1} \mathrm{H}$ NMR spectrum of La and Buta with 1:0.5 molar ratio, which was in good agreement with the extraction yield of rutaecarpine. It is possible to speculate that a high number of hydrogen bonds have a positive influence on extraction efficiency. 
Table 4. Chemical shifts and relative numbers of some protons in the ${ }^{1} \mathrm{H}$ NMR spectra of La-Buta DESs with different molar ratios $\left(500 \mathrm{MHz}, \mathrm{DMSO}-d_{6}, \delta\right.$ in ppm).

\begin{tabular}{|c|c|c|c|c|c|c|c|}
\hline \multirow[b]{2}{*}{ Molar Ratio } & \multicolumn{4}{|c|}{ Levulinic Acid } & \multicolumn{3}{|c|}{ 1,4-Butanediol } \\
\hline & $\underset{1}{\mathrm{COOH}}$ & $\frac{\mathrm{CH}_{2}}{2}$ & $\frac{\mathrm{CH}_{2}}{3}$ & $\frac{\mathrm{CH}_{3}}{4}$ & $\underset{1}{\mathrm{CH}_{2} \mathrm{OH}}$ & $\frac{\mathrm{CH}_{2} \mathrm{OH}}{2}$ & $\frac{\mathrm{CH}_{2}}{3}$ \\
\hline 1:0.5 & $\begin{array}{c}12.05^{\mathrm{a}} \\
(1.08 \mathrm{H})^{\mathrm{b}}\end{array}$ & 2.65 & 2.38 & $\begin{array}{l}2.09 \\
(3 \mathrm{H})\end{array}$ & $\begin{array}{c}4.34 \\
(1.09 \mathrm{H})^{\mathrm{c}}\end{array}$ & 3.38 & $\begin{array}{l}1.43 \\
(2 \mathrm{H})\end{array}$ \\
\hline $1: 1$ & $\begin{array}{c}12.08 \\
(0.80 \mathrm{H})\end{array}$ & 2.64 & 2.38 & $\begin{array}{l}2.09 \\
(3 \mathrm{H})\end{array}$ & $\begin{array}{c}4.35 \\
(0.89 \mathrm{H})\end{array}$ & 3.38 & $\begin{array}{l}1.43 \\
(2 \mathrm{H})\end{array}$ \\
\hline $1: 2$ & $\begin{array}{c}12.04 \\
(0.98 \mathrm{H})\end{array}$ & 2.65 & 2.38 & $\begin{array}{l}2.09 \\
(3 \mathrm{H})\end{array}$ & $\begin{array}{c}4.34 \\
(0.98 \mathrm{H})\end{array}$ & 3.38 & $\begin{array}{l}1.43 \\
(2 \mathrm{H})\end{array}$ \\
\hline
\end{tabular}

${ }^{a}$ The chemical shift of the proton underlined. ${ }^{b}$ The relative integrated area of the proton in the carboxyl group (relative to the protons on the methyl group). ${ }^{\mathrm{c}}$ The relative integrated area of the proton in the hydroxyl group (relative to the protons on the unoxygenated methylene).

\subsection{Effect of Water Content in La-Buta DES}

La-Buta DESs (1:0.5, molar ratio) with different concentrations of water $(5 \%, 10 \%, 15 \%, 20 \%$, $25 \%, 50 \%, 75 \%, w / w)$ were evaluated for the extraction capacity of rutaecarpine. As can be seen in Figure 7 , the extraction yields increased gradually among the percentages of water from $5 \%$ to $25 \%$, and declined suddenly when the percentages of water exceed $25 \%$. The addition of water to the DES system at a certain level improved the extraction efficiency, because this reduces the viscosity of DES, and therefore allows a better mass-transfer rate. However, excessive water in DES could decrease the hydrogen bond interconnection resulting in the decrease in extraction of the target compound $[29,39]$. The yield of rutaecarpine was the highest when the water addition was 25\% in La-Buta DES with 1:0.5 molar ratio.

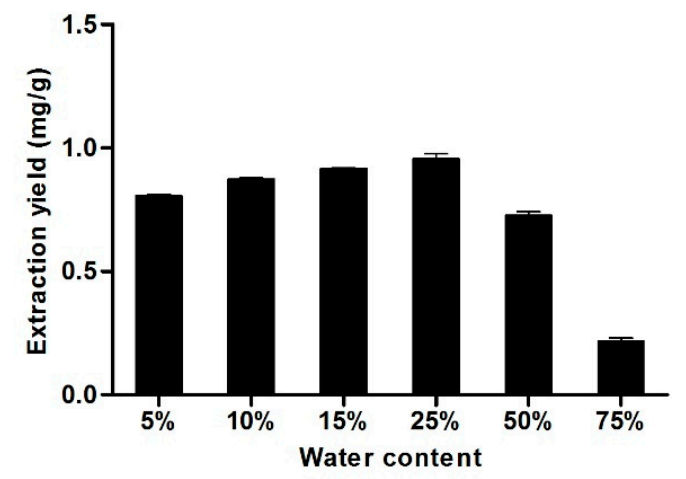

Figure 7. Rutaecarpine extraction yields of La-Buta DESs (1:0.5, molar ratio) diluted with different percentages of water. La-Buta DES aqueous solution (1:0.5, molar ratio) diluted with different percentages of water was used as a solvent to extract at a solid-liquid ratio of 1:50 with ultrasound at $35^{\circ} \mathrm{C}$ and $500 \mathrm{~W}$ for $40 \mathrm{~min}$. Data represent mean \pm S.D. of triplicated experiments.

\subsection{Effect of Extraction Temperature}

General trends indicate that the extraction efficiency can be enhanced by increasing the operating temperature appropriately, which is due to the decrease of the viscosity and surface tension of $\mathrm{DES}_{\mathrm{S}}$, thus improving the solubility and coefficient of the target compound. To obtain a higher extraction efficiency, the extraction temperature was optimized between $25^{\circ} \mathrm{C}$ and $65{ }^{\circ} \mathrm{C}$. Rutaecarpine extraction yields obtained in the present study at different extraction temperatures can be seen in Figure 8 . The results indicate that the extraction yield of $0.742 \pm 0.018 \mathrm{mg} / \mathrm{g}$ was obtained at the lowest temperature $25^{\circ} \mathrm{C}$, and the extraction efficiency was enhanced with increasing temperature from $25^{\circ} \mathrm{C}$ to $55^{\circ} \mathrm{C}$; however no further increase took place at the higher temperature $65^{\circ} \mathrm{C}$. Thus, $55^{\circ} \mathrm{C}$ was chosen as the suitable extraction temperature. 


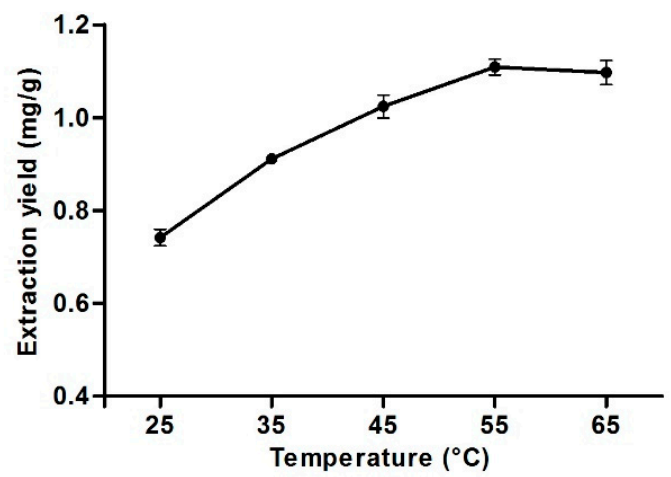

Figure 8. Effect of temperature on the extraction yield of rutaecarpine. La-Buta DES aqueous solution with 1:0.5 molar ratio containing $25 \%$ water was used as a solvent to extract at a solid-liquid ratio of 1:50 with ultrasound at different temperatures and $500 \mathrm{~W}$ for $40 \mathrm{~min}$. The data represent mean \pm S.D. of triplicated experiments.

\subsection{Effect of Solid-Liquid Ratio}

The solid-liquid ratio is another important operating factor affecting the efficiency of an extraction method. The target compound might not be fully extracted when a low ratio of solid to liquid is used, but an excessively high solid-liquid ratio will cause solvent waste, and increase the process cost. The experiment study with five different solid-liquid ratios of 1:10, 1:20, 1:30, 1:40, and 1:50 were conducted. The influence of this solid-liquid ratio is shown in Figure 9.

Increasing the solid-liquid ratio from 1:30 to 1:50 slightly increases the extraction yield; however, for the solid-liquid ratio from 1:10 to 1:30, the change in the extraction yield is very remarkable, as the extraction yield of rutaecarpine increases from $0.625 \pm 0.053 \mathrm{mg} / \mathrm{g}$ to $1.105 \pm 0.009 \mathrm{mg} / \mathrm{g}$, which can be ascribed to favorable mass transfer effects. The use of higher amounts of solvent may not be economically viable, therefore 1:30 was chosen as the optimum ratio to increase extraction efficiency.

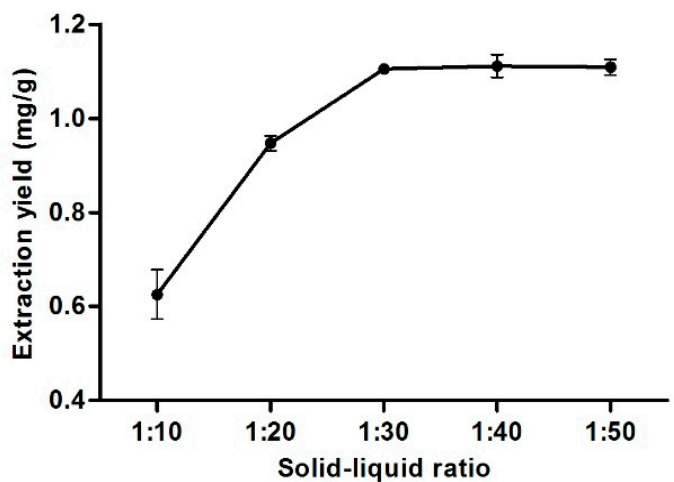

Figure 9. Effect of solid-liquid ratio on the extraction yield of rutaecarpine. La-Buta DES aqueous solution with 1:0.5 molar ratio containing $25 \%$ water was used as the solvent to extract at different solid-liquid ratios with ultrasound at $55^{\circ} \mathrm{C}$ and $500 \mathrm{~W}$ for $40 \mathrm{~min}$. The data represent mean \pm S.D. of triplicated experiments.

\subsection{Effect of Extraction Time}

In consideration of efficient extraction and saving energy, the extraction duration was investigated over a time range 10-60 min. As shown in Figure 10, the amount of rutaecarpine extracted into the DES solution increased rapidly within $40 \mathrm{~min}$. Further prolonging the extraction time lead to no significant change in the extraction efficiency, as dissolution was essentially complete after $40 \mathrm{~min}$. Based on these results, a La-Buta DES aqueous solution with a 1:0.5 molar ratio containing $25 \%$ water used as a solvent to extract at a solid-liquid ratio of 1:30 with ultrasound at $55^{\circ} \mathrm{C}$ and $500 \mathrm{~W}$ for $40 \mathrm{~min}$, was employed. 


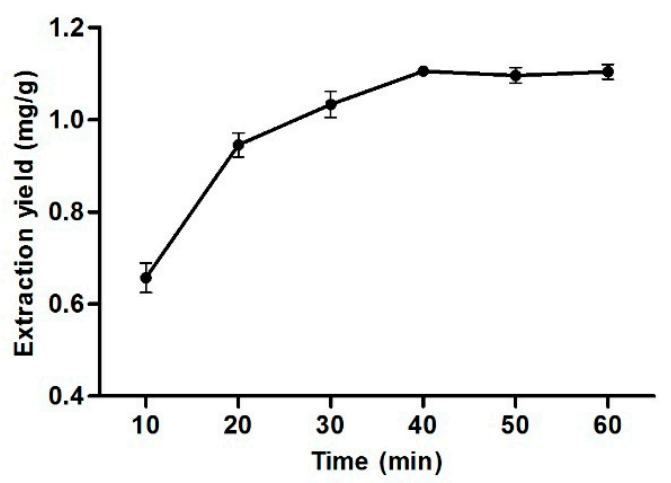

Figure 10. Effect of the solid-liquid ratio on the extraction yield of rutaecarpine. La-Buta DES aqueous solution with 1:0.5 molar ratio containing $25 \%$ water was used as a solvent to extract at a solid-liquid ratio of 1:30 with ultrasound at $55{ }^{\circ} \mathrm{C}$ and $500 \mathrm{~W}$ for different times. The data represent mean \pm S.D. of triplicated experiments.

\subsection{Comparison of Current Extraction Method with Other Extraction Procedures}

The conventional organic solvents, including methanol and $80 \%$ aqueous methanol $(v / v)$, and water ultrasound-assisted extraction, and boiling reflux extraction methods, were chosen to compare with the method developed in this work. The results show in Table 5. The developed ultrasound-assisted extraction conditions that used La-Buta DES aqueous solution with 1:0.5 molar ratio containing $25 \%$ water as the solvent produced the highest extraction yield (sample 1), which was higher than that of the same solvent ultrasound-assisted extraction at $35^{\circ} \mathrm{C}$ (sample 3). Because of the low solubility of rutaecarpine in water, a very low extraction yield of $0.080 \pm 0.001 \mathrm{mg} / \mathrm{g}$ was obtained (sample 4). The conventional organic solvent ultrasound-assisted extraction and boiling reflux extraction methods gave relatively higher extraction yields (samples 5-8). Among them, the $80 \%$ aqueous methanol $(v / v)$ was more effective for rutaecarpine extraction under ultrasound-assisted extraction at $35^{\circ} \mathrm{C}$, which was little lower than that used for the La-Buta DES aqueous solution with 1:0.5 molar ratio containing $25 \%$ water as solvent under the same extraction conditions, and similar to that of the same solvent reflux extraction. Further, with La-Buta DES aqueous solution with 1:0.5 molar ratio containing $25 \%$ water as the solvent, the magnetic stirring method was adopted to extract rutaecarpine at $55^{\circ} \mathrm{C}$ for $40 \mathrm{~min}$ (sample 2). An extraction yield of $1.037 \pm 0.026 \mathrm{mg} / \mathrm{g}$ was obtained, which was little lower than that of the ultrasound-assisted extraction under the same extraction conditions. Analyzing the above results, it could be concluded that the enhancement of extraction yield mainly resulted from the use of La-Buta DES as the solvent, and suitable extraction conditions. 
Table 5. Comparison of the method developed in this work with other extraction procedures for extraction of rutaecarpine in the unripe fruits of T. ruticarpum.

\begin{tabular}{|c|c|c|c|c|}
\hline Sample & Solvent & Method & Extraction Yield (mg/g) & Relative Recovery (\%) ${ }^{a}$ \\
\hline 1 & $\begin{array}{l}\text { La-Buta DES aqueous } \\
\text { solution with 1:0.5 molar } \\
\text { ratio containing } 25 \% \text { water }\end{array}$ & $\begin{array}{l}\text { Ultrasound-assisted extraction } \\
\text { at } 55^{\circ} \mathrm{C} \text { for } 40 \mathrm{~min}\end{array}$ & $1.105 \pm 0.009$ & 100 \\
\hline 2 & $\begin{array}{l}\text { La-Buta DES aqueous } \\
\text { solution with 1:0.5 molar } \\
\text { ratio containing } 25 \% \text { water }\end{array}$ & $\begin{array}{l}\text { Magnetic stirring extraction at } \\
\qquad 55^{\circ} \mathrm{C} \text { for } 40 \mathrm{~min}\end{array}$ & $1.037 \pm 0.026$ & 93.8 \\
\hline 3 & $\begin{array}{l}\text { La-Buta DES aqueous } \\
\text { solution with 1:0.5 molar } \\
\text { ratio containing } 25 \% \text { water }\end{array}$ & $\begin{array}{l}\text { Ultrasound-assisted extraction } \\
\text { at } 35^{\circ} \mathrm{C} \text { for } 40 \mathrm{~min}\end{array}$ & $0.911 \pm 0.011$ & 82.4 \\
\hline 4 & Water & $\begin{array}{l}\text { Ultrasound-assisted extraction } \\
\text { at } 35^{\circ} \mathrm{C} \text { for } 40 \mathrm{~min}\end{array}$ & $0.080 \pm 0.001$ & 7.2 \\
\hline 5 & Methanol [19] & $\begin{array}{l}\text { Ultrasound-assisted extraction } \\
\text { at } 35^{\circ} \mathrm{C} \text { for } 40 \mathrm{~min}\end{array}$ & $0.847 \pm 0.010$ & 76.6 \\
\hline 6 & $\begin{array}{l}\text { 80\% Aqueous methanol } \\
\qquad(v / v)\end{array}$ & $\begin{array}{l}\text { Ultrasound-assisted extraction } \\
\text { at } 35^{\circ} \mathrm{C} \text { for } 40 \mathrm{~min}\end{array}$ & $0.869 \pm 0.002$ & 78.6 \\
\hline 7 & Methanol & $\begin{array}{l}\text { Solvent boiling reflux } \\
\text { extraction for } 30 \mathrm{~min}\end{array}$ & $0.852 \pm 0.006$ & 77.1 \\
\hline 8 & $\begin{array}{l}\text { 80\% Aqueous methanol } \\
\qquad(v / v)[20]\end{array}$ & $\begin{array}{l}\text { Solvent boiling reflux } \\
\text { extraction for } 30 \mathrm{~min}\end{array}$ & $0.858 \pm 0.013$ & 77.6 \\
\hline
\end{tabular}

${ }^{a}$ Relative recovery to that of La-Buta DES aqueous solution with 1:0.5 molar ratio containing $25 \%$ water used as a solvent to extract at a solid-liquid ratio of $1: 30$ with ultrasound at $55^{\circ} \mathrm{C}$ and $500 \mathrm{~W}$ for $40 \mathrm{~min}$.

\subsection{Application of rutaecarpine Extraction in Chinese Patent Medicines}

To extend the application scope of La-Buta DES on the extraction of rutaecarpine, the extraction efficiencies of La-Buta DES on the analytical sample preparation of rutaecarpine in Zuojin Pill and Wuji Pill were investigated. Zoujin Pill, comprising the powders of Coptidis Rhizoma and Euodiae Fructus in the ratio of 6:1 using water as an excipient, and Wuji Pill, comprising the powders of Coptidis Rhizoma, Euodiae Fructus, and Paeoniae Radix Alba in the ratio of 6:1:6, using water as the excipient, are famous Chinese patent medicines that have been recorded in the Chinese Pharmacopeia, and employed in treating gastrointestinal disorders. Several procedures with conventional organic solvents have been applied for the extraction of rutaecarpine to determine the amount thereof in these Chinese patent medicines Zuojin Pill and Wuji Pill [40-43]. In this study, the proposed extraction method was used to analyze rutaecarpine in the Zuojin Pill and Wuji Pill made by pharmaceutical manufacturers and available at the drugstore. Representative HPLC chromatograms of extracts from both the Zuojin Pill and Wuji Pill are shown in Figure 11. The samples were also analyzed after conventional solvent boiling reflux extraction using ethanol as the solvent and the ultrasound-assisted extraction using methanol as the solvent for comparison. The contents of rutaecarpine in different samples are summarized in Table 6. For both the Zuojin Pill and the Wuji Pill, La-Buta DES as solvent exhibited a higher extraction efficiency than that using ethanol or methanol as the solvent. Moreover, the proposed extraction method based upon La-Buta DES is an environmentally friendly extraction technique. 

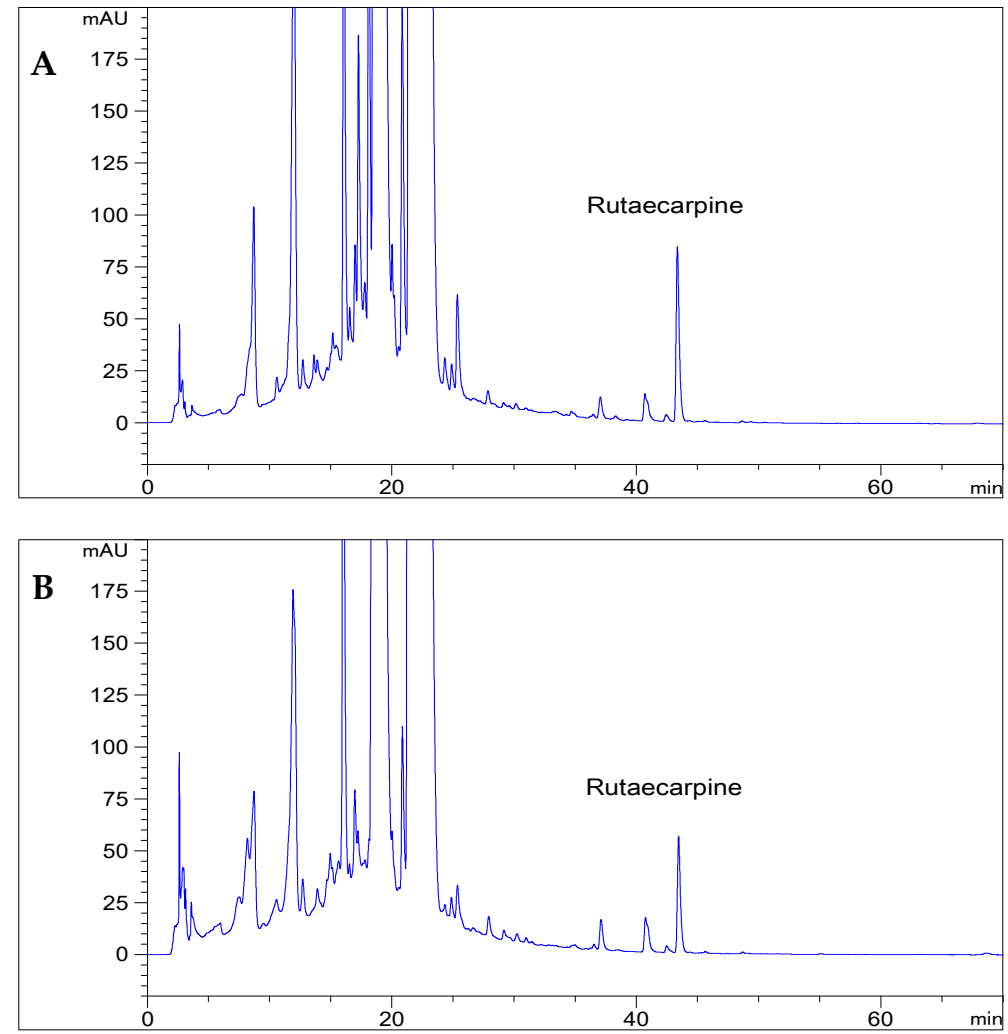

Figure 11. Typical HPLC chromatograms of (A) extract of Zuojin Pill and (B) extract of Wuji Pill. HPLC conditions: Column, Zorbax SB-C18 $250 \mathrm{~mm} \times 4.6 \mathrm{~mm}$ I.D.; column temperature, $35^{\circ} \mathrm{C}$; mobile phase, water with $0.2 \%$ phosphoric acid (A) and acetonitrile (B); gradient program, 0-20 min, 10-30\% B; 20-60 $\mathrm{min}, 30-70 \% \mathrm{~B} ; 60-70 \mathrm{~min}, 70 \% \mathrm{~B}$; flow rate, $1.0 \mathrm{~mL} / \mathrm{min}$, detection wavelength, $345 \mathrm{~nm}$.

Table 6. Comparison of the method developed in this work with other extraction procedures for extraction of rutaecarpine in the Zuojin Pill and Wuji Pill.

\begin{tabular}{cccccc}
\hline Entry & Sample & Solvent & Method & $\begin{array}{c}\text { Extraction } \\
\text { Yield (mg/g) }\end{array}$ & Ref. \\
\hline 1 & Zuojin Pill & $\begin{array}{c}\text { La-Buta DES aqueous solution } \\
\text { with 1:0.5 molar ratio } \\
\text { containing } 25 \% \text { water }\end{array}$ & $\begin{array}{c}\text { Ultrasound-assisted extraction } \\
\text { at } 55^{\circ} \mathrm{C} \text { for } 40 \text { min }\end{array}$ & $0.346 \pm 0.006$ & This work \\
\hline 2 & Zuojin Pill & Ethanol & $\begin{array}{c}\text { Solvent boiling reflux } \\
\text { extraction for } 60 \text { min }\end{array}$ & $0.204 \pm 0.031$ & {$[40]$} \\
\hline 3 & Zuojin Pill & Methanol & $\begin{array}{c}\text { Ultrasound-assisted extraction } \\
\text { at } 25^{\circ} \mathrm{C} \text { for } 45 \text { min }\end{array}$ & $0.256 \pm 0.002$ \\
\hline 4 & Wuji Pill & $\begin{array}{c}\text { La-Buta DES aqueous solution } \\
\text { with 1:0.5 molar ratio } \\
\text { containing 25\% water }\end{array}$ & $\begin{array}{c}\text { Ultrasound-assisted extraction } \\
\text { at } 55^{\circ} \mathrm{C} \text { for } 40 \text { min }\end{array}$ & $0.146 \pm 0.006$ & This work \\
\hline 5 & Wuji Pill & Ethanol & $\begin{array}{c}\text { Solvent boiling reflux } \\
\text { extraction for } 60 \text { min }\end{array}$ & $0.065 \pm 0.006$ & {$[42]$} \\
\hline 6 & Wuji Pill & Methanol & $\begin{array}{c}\text { Ultrasound-assisted extraction } \\
\text { at } 25^{\circ} \mathrm{C} \text { for } 45 \text { min }\end{array}$ & $0.052 \pm 0.002$ & {$[43]$} \\
\hline
\end{tabular}

\section{Conclusions}

A novel and environmentally friendly DESs-based ultrasound-assisted extraction method was developed for extracting the bioactive indolopyridoquinazolinone alkaloid rutaecarpine from the unripe fruits of T. ruticarpum. Among the DESs tested here, La-Buta DES, which was prepared for the first time, with 1:0.5 molar ratio containing 25\% water, was tailor-made to provide a higher extraction efficiency than any conventional organic solvent for the extraction of rutaecarpin. Optimization of the operational conditions improved the extraction efficiency, and the final optimized conditions were as 
follows: Solid-liquid ratio: 1:30; extraction temperature: $55^{\circ} \mathrm{C}$; extraction time: $40 \mathrm{~min}$ in a sonicator bath. The proposed method was successfully applied for the extraction of rutaecarpine from Chinese patent medicines containing the unripe fruits T. ruticarpum with satisfactory extraction efficiency, indicating that the developed method is a promising tool using a sustainable and safe extraction media for the analytical sample preparation of rutaecarpine in complex samples.

Author Contributions: The contributions of the respective authors are as follows: Y.-Y.S. and Y.L. performed the preparation and physicochemical properties tests of DESs. H.-L.S. and J.W. carried out the HPLC analysis of rutaecarpine. K.Z. engaged in NMR experiments. S.-W.S. and K.L. contribute to checking and confirming all of the procedures of the preparation and analysis. This study was performed based on the design of W.W., the corresponding author. All the authors read and approved the final manuscript.

Funding: This research was funded by Shandong Provincial Natural Science Foundation, China, grant numbers ZR2018BD030 and ZR2016HB22.

Conflicts of Interest: The authors declare no conflict of interest.

\section{References}

1. Piska, K.; Gunia-Krzyżak, A.; Koczurkiewicz, P.; Wójcik-Pszczoła, K.; Pękala, E. Piperlongumine (piplartine) as a lead compound for anticancer agents-Synthesis and properties of analogues: A mini-review. Eur. J. Med. Chem. 2018, 156, 13-20. [CrossRef] [PubMed]

2. Khan, H.; Hadda, T.B.; Touzani, R. Diverse therapeutic potential of nitidine, a comprehensive review. Curr. Drug Metab. 2018, 19, 986-991. [CrossRef] [PubMed]

3. Sharma, V.; Sharma, P.C.; Kumar, V. A mini review on pyridoacridines: Prospective lead compounds in medicinal chemistry. J. Adv. Res. 2015, 6, 63-71. [CrossRef] [PubMed]

4. Ding, J.S.; Gao, R.; Li, D.; Peng, J.; Ran, L.L.; Li, Y.J. Solid dispersion of rutaecarpine improved its antihypertensive effect in spontaneously hypertensive rats. Biopharma. Drug Dispos. 2008, 29, 495-500. [CrossRef]

5. Borrelli, F.; Campagnuolo, C.; Capasso, R.; Fattorusso, E.; Taglialatela-Scafati, O. Iodinated indole alkaloids from Plakortis simplex - New plakohypaphorines and an evaluation of their antihistamine activity. Eur. J. Org. Chem. 2004, 2004, 3227-3232. [CrossRef]

6. Shao, H.; Yang, Y.; Mi, Z.; Zhu, G.X.; Qi, A.P.; Ji, W.G.; Zhu, Z.R. Anticonvulsant effect of rhynchophylline involved in the inhibition of persistent sodium current and NMDA receptor current in the pilocarpine rat model of temporal lobe epilepsy. Neuroscience 2016, 337, 355-369. [CrossRef]

7. De Castro Cunha, A.; Chierrito, T.P.C.; De Carvalho, G.M.; Leon, L.L.P.; da Silva, C.C.; Tanaka, J.C.; de Souza, L.M.; Gonçalves, R.A.C.; de Oliveira, A.J.B. Anti-leishmanial activity of alkaloidal extracts obtained from different organs of Aspidosperma ramiflorum. Phytomedicine 2012, 19, 413-417. [CrossRef]

8. Nandini, H.S.; Naik, P.R. Antidiabetic, antihyperlipidemic and antioxidant effect of vincamine, in streptozotocin-induced diabetic rats. Eur. J. Pharmacol. 2019, 843, 233-239. [CrossRef]

9. Liu, Y.P.; Liu, Q.L.; Zhang, X.L.; Niu, H.Y.; Guan, C.Y.; Sun, F.K.; Xu, W.; Fu, Y.H. Bioactive monoterpene indole alkaloids from Nauclea officinalis. Bioorg. Chem. 2019, 83, 1-5. [CrossRef]

10. Huang, Y.X.; Tan, H.X.; Guo, Z.Y.; Wu, X.X.; Zhang, Q.L.; Zhang, L.; Diao, Y. The biosynthesis and genetic engineering of bioactive indole alkaloids in plants. J. Plant Biol. 2016, 59, 203-214. [CrossRef]

11. Yang, Y.; Zuo, W.J.; Zhao, Y.X.; Dong, W.H.; Mei, W.L.; Dai, H.F. Indole alkaloids from Kopsia hainanensis and evaluation of their antimicrobial activity. Planta Med. 2012, 78, 1881-1884. [CrossRef] [PubMed]

12. Son, J.; Chang, H.W.; Jahng, Y. Progress in studies on rutaecarpine. II.-Synthesis and structure-biological activity relationships. Molecules 2015, 20, 10800-10821. [CrossRef]

13. Wang, C.H.; Hao, Z.Y.; Zhou, J.; Zhang, L.; Sun, Y.X.; Liang, C.Z. Rutaecarpine alleviates renal ischemia reperfusion injury in rats by suppressing the JNK/p38 MAPK signaling pathway and interfering with the oxidative stress response. Mol. Med. Rep. 2017, 16, 922-928. [CrossRef] [PubMed]

14. Yang, Y.M.; Chen, Q.Q.; Jia, S.J.; He, L.M.; Wang, A.P.; Li, D.; Li, Y.J.; Li, X.H. Involvement of TRPV1 in the expression and release of calcitonin gene-related peptide induced by tutaecarpine. Mol. Med. Rep. 2018, 17, 5168-5174. [CrossRef]

15. Tian, K.M.; Li, J.J.; Wu, S.W. Rutaecarpine: A promising cardiovascular protective alkaloid from Evodia Rutaecarpa (Wu Zhu Yu). Pharmacol. Res. 2019, 141, 541-550. [CrossRef] [PubMed] 
16. Ruesgas-Ramón, M.; Figueroa-Espinoza, M.C.; Durand, E. Application of deep eutectic solvents (DES) for phenolic compounds extraction: Overview, challenges, and opportunities. J. Agric. Food Chem. 2017, 65, 3591-3601. [CrossRef] [PubMed]

17. Yang, W.T.; Huang, S.X.; Xu, W.G.; Wu, S.J. Optimization of ultrasonic-assisted extracting of evodiamine and rutaecarpine. Food Res. Dev. 2016, 37, 54-57. [CrossRef]

18. Lu, S.F.; Wang, Y.R. Optimization of the extraction procedure of Evodia fruits by the uniform design and orthogonal design. J. Beijing Univ. Tradit. Chin. Med. 2004, 27, 66-70. [CrossRef]

19. Pellati, F.; Benvenuti, S.; Yoshizaki, F.; Melegari, M. Development and validation of HPLC methods for the analysis of phenethylamine and indoloquinazoline alkaloids in Evodia species. J. Sep. Sci. 2006, 29, 641-649. [CrossRef]

20. Tang, X.L.; Huang, Z.F.; Chen, Y.; Liu, Y.H.; Liu, Y.H.; Zhao, J.N.; Yi, J.H. Simultaneous determination of six bioactive compounds in Evodiae Fructus by high-performance liquid chromatography with diode array detection. J. Chromatogr. Sci. 2014, 52, 149-156. [CrossRef]

21. Takla, S.S.; Shawky, E.; Hammoda, H.M.; Darwish, F.A. Green techniques in comparison to conventional ones in the extraction of Amaryllidaceae alkaloids: best solvent selection and parameters optimization. J. Chromatogr. A 2018, 1567, 99-110. [CrossRef]

22. Liu, B.; Guo, F.; Chang, Y.L.; Jiang, H.L.; Wang, Q. Optimization of extraction of evodiamine and rutaecarpine from fruit of Evodia rutaecarpa using modified supercritical $\mathrm{CO}_{2}$. J. Chromatogr. A 2010, 1217, 7833-7839. [CrossRef]

23. Su, E.Z.; Yang, M.; Cao, J.; Lu, C.; Wang, J.H.; Cao, F.L. Deep eutectic solvents as green media for efficient extraction of terpene trilactones from Ginkgo biloba leaves. J. Liq. Chromatogr. Relat. Technol. 2017, 40, 385-391. [CrossRef]

24. Dai, Y.T.; Witkamp, G.J.; Verpoorte, R.; Choi, Y.H. Tailoring properties of natural deep eutectic solvents with water to facilitate their applications. Food Chem. 2015, 187, 14-19. [CrossRef] [PubMed]

25. Jiang, Z.M.; Wang, L.J.; Gao, Z.; Zhuang, B.; Yin, Q.; Liu, E.H. Green and efficient extraction of different types of bioactive alkaloids using deep eutectic solvents. Microchem. J. 2019, 145, 345-353. [CrossRef]

26. Tang, W.Y.; Li, G.Z.; Chen, B.Q.; Zhu, T.; Row, K.H. Evaluating ternary deep eutectic solvents as novel media for extraction of flavonoids from Ginkgo biloba. Sep. Sci. Technol. 2017, 52, 91-99. [CrossRef]

27. Zhuang, B.; Dou, L.L.; Li, P.; Liu, E.H. Deep eutectic solvents as green media for extraction of flavonoid glycosides and aglycones from Platyladi Cacumen. J. Pharm. Biomed. 2017, 134, 214-219. [CrossRef]

28. Jeong, K.M.; Ko, J.; Zhao, J.; Jin, Y.; Yoo, D.E.; Han, S.Y. Mult-functioning deep eutectic solvents as extraction and storage media for bioactive natural products that are readily applicable to cosmetic products. J. Clean. Prod. 2017, 151, 87-95. [CrossRef]

29. Huang, Y.; Feng, F.; Jiang, J.; Qiao, Y.; Wu, T.; Voglmeir, J.; Chen, Z.G. Green and efficient extraction of rutin from tartary buckwheat hull by using natural deep eutectic solvents. Food Chem. 2017, 221, 1400-1405. [CrossRef] [PubMed]

30. Duan, L.; Dou, L.L.; Guo, L.; Li, P.; Liu, E.H. Comprehensive evaluation of deep eutectic solvents in extraction of bioactive natural products. ACS Sustain. Chem. Eng. 2016, 4, 2405-2411. [CrossRef]

31. Craveiro, R.; Aroso, I.; Flammia, V.; Carvalho, T.; Viciosa, M.T.; Dionísio, M.; Barreiros, S.; Reis, R.L.; Duarte, A.R.C.; Paiva, A. Properties and thermal behavior of natural deep eutectic solvents. J. Mol. Liq. 2016, 215, 534-540. [CrossRef]

32. Dai, Y.; van Spronsen, J.; Witkamp, G.J.; Verpoorte, R.; Choi, Y.H. Natural deep eutectic solvents as new potential media for green technology. Anal. Chim. Acta 2013, 766, 61-68. [CrossRef]

33. Wang, M.; Wang, J.Q.; Zhou, Y.Y.; Zhang, M.Y.; Xia, Q.; Bi, W.T.; Chen, D.D.Y. Ecofriendly mechanochemical extraction of bioactive compounds from plant with deep eutectic solvents. ACS Sustain. Chem. Eng. 2017, 5, 6297-6303. [CrossRef]

34. Liu, Y.; Friesen, J.B.; McAlpine, J.B.; Lankin, D.C.; Chen, S.N.; Pauli, G.F. Natural deep eutectic solvent: Properties applications, and perspectives. J. Nat. Prod. 2018, 81, 679-690. [CrossRef]

35. Francisco, M.; van den Bruinhorst, A.; Kroon, M.C. Low-transition-temperature mixtures (LTTMs): A new generation of designer solvent. Angew. Chem. Int. Ed. 2013, 52, 3074-3085. [CrossRef] [PubMed]

36. Bubalo, M.C.; Ćurko, N.; Tomašević, M.; Ganić, K.K.; Redovniković, R. Green extraction of grape skin phenolics by using deep eutectic solvents. Food Chem. 2016, 200, 159-166. [CrossRef] 
37. Zhang, P.T.; Pan, B.Y.; Liao, Q.F.; Yao, M.C.; Xu, X.J.; Wan, J.Z.; Liu, D.; Xie, Z.Y. Simultaneous quantification of limonin, two indolequinazoline alkaloids, and four quinolone alkaloids in Evodia rutaecarpa (Juss.) Benth by HPLC-DVD method. J. Anal. Methods Chem. 2013, 2013, 827361. [CrossRef] [PubMed]

38. Nam, M.W.; Zhao, J.; Lee, M.S.; Jeong, J.H.; Lee, J. Enhanced extraction of bioactive natural products using tailor-made deep eutectic solvents: Application to flavonoid extraction from Flos sophorae. Green Chem. 2015, 17, 1718-1727. [CrossRef]

39. Cui, Q.; Peng, X.; Yao, X.H.; Wei, Z.F.; Luo, M.; Wang, W.; Zhao, C.J.; Fu, Y.J.; Zu, Y.G. Deep eutectic solvent-based microwave-assisted extraction of genistin, genis-tein and apigenin from pigeon pea roots. Sep. Purif. Technol. 2015, 150, 63-72. [CrossRef]

40. Zhang, J.; Zhang, F.; Jiang, L.; Jiang, R.; Tan, S.J. Determination of evodiamine and rutaecarpine in Wiji Wan by HPLC. Chin. J. Chin. Mater. Med. 2003, 38, 1193-1194. [CrossRef]

41. Zhang, X.F.; Qiu, F.R.; Jiang, J.; Gao, C.L.; He, M. Simultaneous determination of 6 alkaloids in Zuojin Pill and Xianglian Pill by LC-MS/MS. Chin. Traditi. Pat. Med. 2010, 32, 597-600. [CrossRef]

42. Tan, S.J.; Zhao, B.C.; Wang, H.T.; Li, J.L.; Chu, F. Determination of evodiamine and rutaecarpine in Wiji Wan by HPLC. Pharm. J. Chin. P. L. A. 2002, 18, 201-204. [CrossRef]

43. Luo, D.L.; Xi, X.R.; Gao, Y.M.; Qi, Y.D.; Huang, P. Determination of evodiamine and rutaecarpine in Wiji Wan by micellar electrokinetic capillary chromatography. Chin. J. Chin. Mater. Med. 2007, 32, 1936-1938. [CrossRef]

(C) 2019 by the authors. Licensee MDPI, Basel, Switzerland. This article is an open access article distributed under the terms and conditions of the Creative Commons Attribution (CC BY) license (http:// creativecommons.org/licenses/by/4.0/). 